Louisiana State University

LSU Digital Commons

Faculty Publications

Department of Biological Sciences

6-16-2006

\title{
STAT5 activators modulate acyl CoA oxidase (AOX) expression in adipocytes and STAT5A binds to the AOX promoter in vitro
}

Ann A. Coulter

Louisiana State University

Jacqueline M. Stephens

Louisiana State University

Follow this and additional works at: https://digitalcommons.Isu.edu/biosci_pubs

\section{Recommended Citation}

Coulter, A., \& Stephens, J. (2006). STAT5 activators modulate acyl CoA oxidase (AOX) expression in adipocytes and STAT5A binds to the AOX promoter in vitro. Biochemical and Biophysical Research Communications, 344 (4), 1342-1345. https://doi.org/10.1016/j.bbrc.2006.04.071

This Article is brought to you for free and open access by the Department of Biological Sciences at LSU Digital Commons. It has been accepted for inclusion in Faculty Publications by an authorized administrator of LSU Digital Commons. For more information, please contact ir@lsu.edu. 


\title{
STAT5 activators modulate acyl CoA oxidase (AOX) expression in adipocytes and STAT5A binds to the AOX promoter in vitro
}

\author{
Ann A. Coulter, Jacqueline M. Stephens * \\ Department of Biological Sciences, Louisiana State University, 202 Life Sciences Bldg., Baton Rouge, LA 70803, USA
}

Received 28 March 2006

Available online 25 April 2006

\begin{abstract}
Growth hormone $(\mathrm{GH})$ diminishes adipose tissue mass in vivo and prolactin (PRL) can also modulate adipocyte metabolism. Both GH and PRL are potent activators of STAT5 and exert a variety of effects on adipocyte gene expression. In this study, we have demonstrated that GH and PRL increase the mRNA of acyl CoA oxidase in 3T3-L1 adipocytes. We also identified seven putative STAT elements in the murine AOX promoter. We observed that GH modulates protein binding to the majority of these promoter elements. However, GH induced very potent binding to -1841 to -1825 of the murine AOX promoter. EMSA supershift analysis revealed that this site was specifically bound by STAT5A, but not by STAT1 or STAT3. Taken together, these data strongly suggest that GH directly induces the expression of AOX in adipocytes through STAT5A binding to the -1841 to -1825 site within the AOX promoter. Our observations are consistent with other studies that demonstrate that STAT5 activators modulate fatty acid oxidation.
\end{abstract}

(c) 2006 Elsevier Inc. All rights reserved.

Keywords: STAT5; Acyl CoA oxidase; Adipocyte; Growth hormone; Prolactin

Growth hormone $(\mathrm{GH})$ is known to have profound effects on lipid metabolism [1]. The effects of PRL have been well characterized in mammary tissues, yet there is also evidence demonstrating that this hormone can affect adipose tissue in mice and humans [2,3]. However, few direct molecular targets for the actions of GH and PRL on adipocyte metabolism have been identified. It is well known that GH and PRL induce signaling via the JAKSTAT pathway. In particular, STAT 5 proteins are potently activated by these two hormones [4]. Also, multiple lines of evidence suggest that STAT5 proteins can modulate adipocyte function.

During differentiation of 3T3-L1 adipocytes, the expression levels of STAT5A and 5B are highly induced [5] and GH dependent adipogenesis of 3T3-F442A cells

\footnotetext{
This work was supported by Grant R01DK52968 from the National Institutes of Health to J.M.S.

* Corresponding author. Fax: +1 2255782597.

E-mail address: jsteph1@1su.edu (J.M. Stephens).
}

is attenuated by STAT5 anti-sense oligonucleotides [6]. Also, constitutively active STAT5 can replace the requirement for $\mathrm{GH}$ in adipogenesis of these cells [7]. Moreover, ectopic expression of STAT5A has been shown to confer adipogenesis in 3T3-L1 preadipocytes [8] and in two different non-precursor cell lines [9]. Transgenic deletion of STAT5A, STAT5B, or both STAT5 genes in mice results in significantly reduced fat pad sizes compared to wild-type mice [10], further evidence that STAT proteins play a role in adipogenesis. Yet, in primary cultures of adipose tissue from these animals, GH did not stimulate lipolysis as it does in adipocytes from wild-type animals [11], suggesting that some of the effects of GH on fat metabolism in mature adipocytes also are dependent on STAT5 proteins. However, very few studies have identified specific direct STAT5 target genes in adipocytes. We recently observed that the GH and PRL inhibition of fatty acid synthase transcription was mediated by a STAT5A binding site in the rat FAS promoter [12]. Hence, our current efforts have 
been to identify other genes associated with fatty acid metabolism that are directly modulated by STAT5 proteins in fat cells.

In this study, we examined the modulation of acyl CoA oxidase (AOX), a rate-limiting enzyme in peroxisomal fatty acid oxidation. This is the first study to demonstrate that both GH and PRL modulate AOX expression in fat cells. Moreover, we identified seven STAT elements in the AOX promoter and demonstrated that binding to these sites was modulated by GH. Finally, our in vitro studies have demonstrated that the specific binding to the -1841 to -1825 site in the murine AOX promoter is mediated by STAT5A.

\section{Materials and methods}

Materials. Dulbecco's modified Eagle's medium (DMEM) and fetal bovine serum (FBS) were purchased from Invitrogen. STAT1 antibody was purchased from Upstate Biotechnology. STAT3 and STAT5A antibodies were purchased from Santa Cruz. Porcine growth hormone (GH) and ovine prolactin (PRL) were purchased from Sigma. Taqman RT-PCR reagent mix was from Applied Biosystems and fluorescent Taqman probes (FAM/BHQ) were purchased from Biosearch Technologies. $\left[\alpha^{3}{ }^{32} \mathrm{P}\right] \mathrm{dCTP}$ and deoxynucleotides were purchased from Amersham. Klenow fragment was from Promega.

Cell culture. Murine 3T3-L1 preadipocytes were plated and grown to 2 days post confluence in DMEM with $10 \%$ bovine serum. Medium was changed every $48 \mathrm{~h}$. Cells were induced to differentiate by changing the medium to DMEM containing $10 \%$ fetal bovine serum, $0.5 \mathrm{mM} 3$-isobutyl-1-methylxanthine, $1 \mu \mathrm{M}$ dexamethasone, and $1.7 \mu \mathrm{M}$ insulin. This medium was replaced with DMEM containing $10 \%$ fetal bovine serum and $425 \mathrm{nM}$ insulin for $48 \mathrm{~h}$. Adipocytes were then maintained in DMEM with $10 \%$ fetal bovine serum for at least eight days. Adipocytes were serum deprived in DMEM with $0.15 \%$ BSA overnight before treatment with GH or PRL.

Nuclear and cytosolic extract preparation. Monolayers of 3T3-L1 adipocytes were harvested in a nuclear homogenization buffer (NHB) as described [13]. Nonidet P-40 was added to a final concentration of $0.15 \%$, and cells were homogenized with 16 strokes in a Dounce homogenizer. Homogenates were centrifuged at $1500 \mathrm{rpm}$ for $6 \mathrm{~min}$ at $4{ }^{\circ} \mathrm{C}$. The supernatants were saved and frozen as cytosolic extracts and the pellets of intact nuclei were resuspended in half of the previous volume of NHB and centrifuged as before. The pellet of intact nuclei was resuspended in a buffer of $20 \mathrm{mM}$ Hepes, pH 7.9, $0.42 \mathrm{M} \mathrm{NaCl}, 1.5 \mathrm{mM} \mathrm{MgCl}_{2}, 0.2 \mathrm{mM}$ EDTA, and $25 \%$ glycerol. For electromobility shift assays, the nuclear extracts were incubated on ice for at least $30 \mathrm{~min}$ and then drawn twice through a 20 gauge needle. Nuclei were centrifuged for $10 \mathrm{~min}$ at $10,000 \mathrm{rpm}$ and the supernatants were taken for protein analysis by BCA or stored in aliquots at $-80^{\circ} \mathrm{C}$.

Electromobility shift assays. Annealed, double-stranded oligonucleotides with GG overhangs were end labeled by a fill-in reaction using DNA polymerase I Klenow fragment in the presence of $\left[\alpha-{ }^{32} \mathrm{P}\right] \mathrm{dCTP}$ as described in detail [14]. End-labeled oligonucleotides were purified from unincorporated $\left[{ }^{32} \mathrm{P}\right] \mathrm{dCTP}$ with Bio-Rad Micro Biospin-6 chromatography columns. Cytoplasmic or nuclear extracts $(15 \mu \mathrm{g})$ were incubated with $2 \mu \mathrm{l}$ of end-labeled oligonucleotides $(50,000 \mathrm{cpm} / \mu \mathrm{l})$ for $30 \mathrm{~min}$ on ice prior to loading on a gel that had been pre-run for $30 \mathrm{~min}$ as described [12]. For cold competition analysis to determine specificity of binding, nuclear extracts were incubated on ice for $15 \mathrm{~min}$ with unlabeled oligo before addition of $\left[{ }^{32} \mathrm{P}\right]$-labeled probe. For supershift analysis, nuclear extracts were preincubated with antibody for one hour at room temperature.

Total RNA extraction and expression analysis. Total RNA was isolated from 3T3-L1 adipocyte monolayers using Trizol (Life Technologies) according to manufacturer's protocols. Total RNA was diluted in water and $14 \mathrm{ng}$ was used per $30 \mu \mathrm{L}$ RT-PCR mixture to quantitatively determine $A O X$ and cyclophilin $B$ mRNA levels using an Applied Biosystems Prism 7000 sequence detection system. Taqman probes and primers were designed with Primer Express software (ABI). Relative values of target gene mRNAs were quantitated from a standard curve and adjusted for total RNA per PCR using cyclophilin B. mRNA values are expressed as means \pm standard error of the mean. Sequences of primers and probes are as follows: acyl CoA oxidasel forward primer CAGCCAG ATTGGTAGAAATTGCT, reverse primer ACGCCACTTCCTTGC TCTTC, and probe CAAAAAACCTTCAGGCCCAAGTGAGTCAC; cyclophilin $B$ forward primer GGTGGAGAGCACCAAGACAGA, reverse primer GCCGGAGTCGACAATGATG, and probe ATCCTTC AGTGGCTTGTCCCGGCT.

\section{Results}

\section{STAT5 activators induce acyl CoA expression in 3T3-L1 adipocytes}

Mature 3T3-L1 adipocytes were treated with either growth hormone or prolactin and Taqman quantitative RT-PCR was performed to determine mRNA levels of acyl CoA oxidase (AOX). As shown in Fig. 1, AOX mRNA was readily detectable in untreated 3T3-L1 adipocytes, but treatment with either GH or PRL resulted in a significant increase in AOX mRNA levels within $30 \mathrm{~min}$. In GH treated adipocytes, the levels of AOX mRNA started to decrease within an hour, but in PRL treated cells AOX mRNA levels did not decline to the same extent.

\section{The identification of STAT binding sites in the AOX promoter}

Since GH and PRL are potent STAT activators, we hypothesized that the AOX promoter may be modulated by these transcription factors. An analysis of the first 2000 base pairs of the promoter revealed seven putative STAT sites (Table 1). We performed electrophoretic mobility shift assays (EMSAs) using nuclear extracts from GH treated 3T3-L1 adipocytes and labeled DNA binding sites to determine if GH induced binding to any of these consensus sites. As shown in Fig. 2, we observed GH dependent binding to the -1841 element. A darker exposure of this blot revealed GH regulated binding to four other STAT elements at $-1362,-1466,-1479$, and -1998 . Although there was protein binding at the other 2 sites $(-561$ and -1978), this interaction was not substantially regulated by GH (bottom panel, Fig. 2). These data demonstrate that five of the seven STAT elements in the AOX promoter bind nuclear adipocytes proteins in a GH dependent manner in vitro.

Since the -1841 element of the AOX promoter appeared to have a substantial amount of protein bound, we further examined protein binding to this element. To examine the specificity, we performed EMSAs with cytosolic extract and nuclear extracts from GH treated 3T3-L1 adipocytes. As shown in Fig. 3A, we only observed binding to the STAT element when samples were incubated with nuclear extracts from $\mathrm{GH}$ treated cells, but no binding was observed with cytosolic extract from GH treated 
Acyl CoA Oxidase mRNA

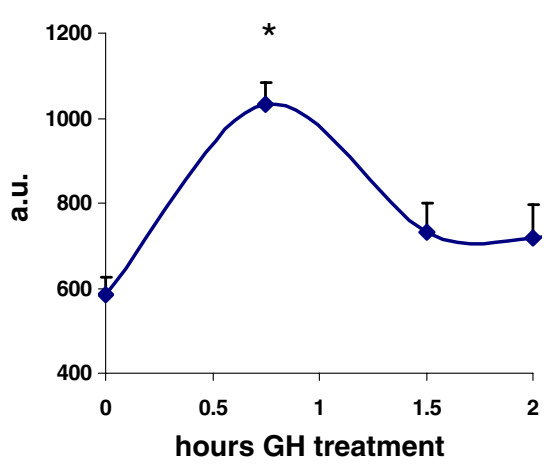

Acyl CoA Oxidase mRNA

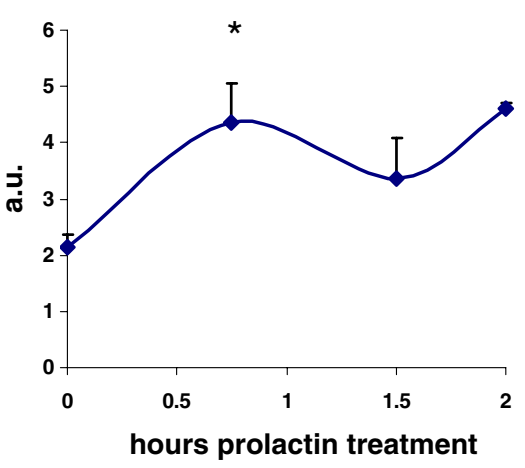

Fig. 1. Growth hormone and prolactin rapidly induce AOX mRNA in 3T3-L1 adipocytes. Total RNA was isolated from fully differentiated 3T3-L1 adipocytes that were treated for the indicated times with $125 \mathrm{ng} / \mathrm{ml}$ growth hormone $(\mathrm{GH})$ or $1 \mathrm{IU} / \mathrm{ml}$ of prolactin. The levels of mRNA expression were determined by quantitative RT-PCR using Taqman probes and primers. Values shown represent mean values of target mRNA per cyclophilin B $\mathrm{mRNA} \pm \mathrm{SE}$ from two independent experiments performed at least in triplicate. Stars indicate a significant difference from control values as determined by Anova single factor analysis with $p<0.01$.

Table 1

STAT sites in the AOX promoter

\begin{tabular}{lll}
\hline Site & Location & Sequence \\
\hline 1 & $(-561$ to -541$)$ & TTTGGGTTCCAGTAAAATCAA \\
2 & $(-1362$ to -1346$)$ & TTTTTTCGAGACAGGGT \\
3 & $(-1466$ to -1448$)$ & ACCCATTCTCAGCACCGTT \\
4 & $(-1479$ to -1461$)$ & CTTCATTCGTTTAACCCAT \\
5 & $(-1841$ to -1825$)$ & TAACTTCTCAGAATTTT \\
6 & $(-1998$ to -1980$)$ & CAAGCTTCTGCTAAGAGGA \\
7 & $(-1978$ to -1959$)$ & TAAAATTCACAAGAACCCAA \\
\hline
\end{tabular}
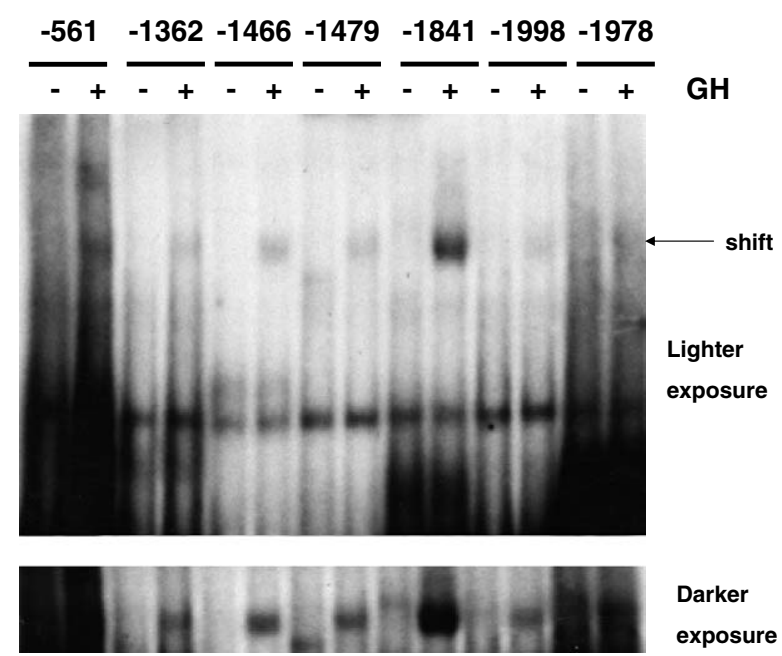

Fig. 2. GH induces binding to putative STAT elements located within the first 2000 bases upstream of the murine AOX promoter. Nuclear extracts were prepared from adipocytes that were untreated $(-)$ or treated $(+)$ with $125 \mathrm{ng} / \mathrm{ml} \mathrm{GH}$ for $15 \mathrm{~min}$ and protein-DNA complexes were resolved by EMSA. For each sample, $15 \mu \mathrm{g}$ of protein was incubated with $100,000 \mathrm{cpm}$ of the indicated $\left[{ }^{32} \mathrm{P}\right]$-labeled probes. A darker exposure of the gel is shown in the lower panel. This is a representative experiment independently performed three times.

adipocytes. Also, GH regulated protein binding to labeled oligonucleotides corresponding to -1841 to -1825 of the AOX promoter was effectively competed with unlabeled wild-type oligonucleotides. As shown in the EMSA in Fig. 3A, the STAT site was only bound by nuclear proteins and not by cytosolic proteins. To determine what STAT proteins comprised the bound complex, we performed supershift analysis with antibodies directed against three different STAT proteins that are expressed in fat cells. As shown in Fig. 3B, the GH sensitive protein complex was completely supershifted by an antibody directed against STAT5A, but was unaffected by STAT1 or STAT3 antibodies.

\section{Discussion}

The novel findings in this study include data demonstrating that AOX levels are increased following stimulation with activators of STAT5 in 3T3-L1 adipocytes, the identification of several GH responsive regions in the murine AOX promoter, and the characterization of a STAT5A binding site in the AOX promoter. These results suggest that STAT5A directly modulates the expression of AOX in adipocytes. Moreover, our data suggest that STAT5A has catabolic functions in murine adipocytes, in addition to its adipogenic and lipogenic capabilities that have been previously been described [7,9].

GH and prolactin (PRL) are potent activators of STAT5 and exert adipogenic effects in preadipocytes. In vivo administration of GH induces lipolysis and lipid oxidation in adipose tissue. Both mitochondria and peroxisomes carry out fatty acid $\beta$-oxidation. The first step of peroxisomal $\beta$-oxidation is catalyzed by acyl-CoA oxidase (AOX). Acyl-CoA oxidase mRNA and protein expression is most abundant in liver followed by kidney, brain, and adipose tissue [15]. Mice lacking AOX have steatohepatitis, spontaneous peroxisome proliferation, and liver tumors [16]. Other studies in AOX deficient mice have revealed that substrates of this enzyme function as ligands for PPAR $\alpha$ and play a role in hepatic lipid metabolism and in the pathogenesis of fatty liver [17]. 

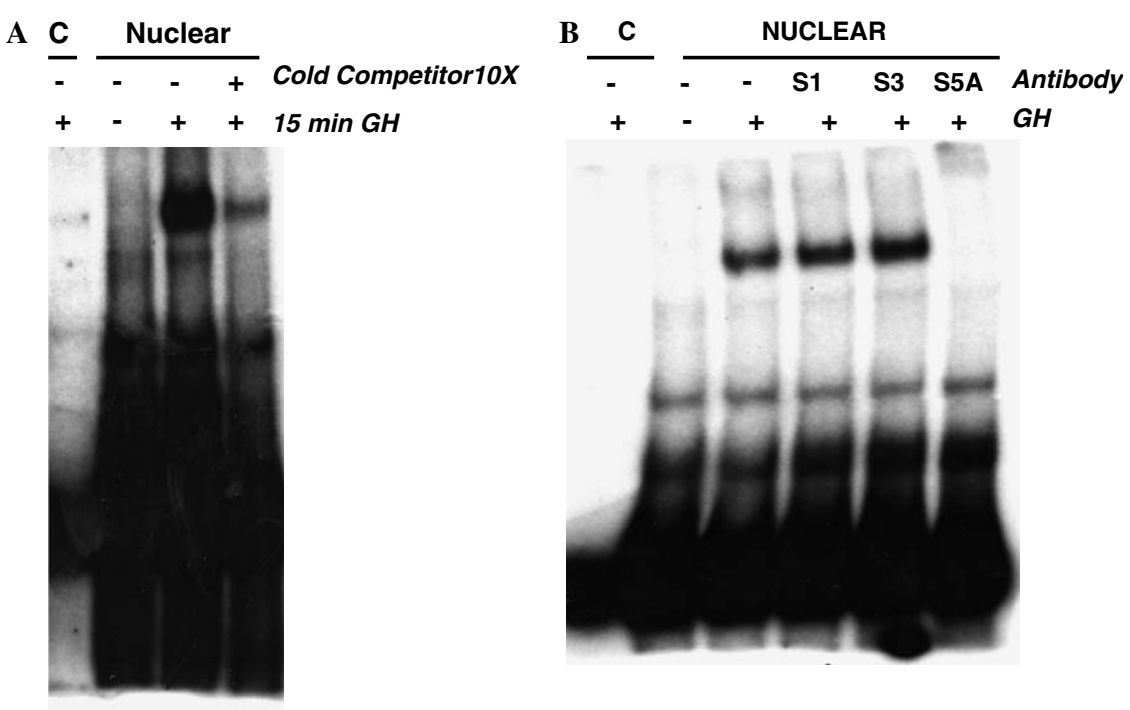

Fig. 3. The specific GH induced binding to -1841 to -1825 of AOX promoter is mediated by STAT5A. (A) Nuclear extracts were prepared from adipocytes that were untreated or treated with $125 \mathrm{ng} / \mathrm{ml} \mathrm{GH}$ for $15 \mathrm{~min}$ and protein-DNA complexes were resolved by EMSA. To demonstrate specificity, nuclear extracts were preincubated with an excess of the indicated unlabeled oligonucleotides (cold competitor). (B) For each sample, $15 \mu \mathrm{g}$ of protein was preincubated with $4 \mu \mathrm{g}$ of the indicated antibody and then incubated with a $\left[{ }^{32} \mathrm{P}\right]$-labeled probe comprising -1841 to -1825 of the AOX promoter. The protein-DNA complexes were resolved by EMSA. This is a representative experiment independently performed two times.

To date, very little is known about the modulation of AOX expression. The promoter regions of the acyl-CoA oxidase contain transcriptional regulatory peroxisome proliferator-response elements (PPREs) [18] which likely mediate the increase in AOX mRNA that is induced by bezafibrate and accompanied by peroxisomal $\beta$-oxidation in white adipose tissue in rats [19]. ACO mRNA levels have also been shown to be modulated in GH transgenic mice [20]. Besides the PPAR $\alpha$ site and the STAT sites that we identified, there has been little characterization of other regulatory elements in the AOX promoter.

There are various studies demonstrating that both GH and PRL play a role in adipose tissue development [21] and we have known for decades that growth hormone is a potent regulator of lipid metabolism [1]. However, few direct molecular targets of $\mathrm{GH}$ have been identified in fat cells. It is well documented that $\mathrm{GH}$ can attenuate fatty acid synthesis and enhance fatty acid oxidation. Our recent studies have shown that the GH induced inhibition of fatty acid synthase expression can be mediated by STAT5A binding to the FAS promoter [12]. In this study, we have shown that STAT5A can also modulate the expression of an enzyme involved in fatty acid oxidation. In conclusion, we hypothesize that STAT5 proteins are important regulators of various genes associated with lipid metabolism.

\section{Acknowledgment}

We thank James E. Baugh Jr. for technical assistance.

\section{References}

[1] M.B. Davidson, Endocr. Rev. 8 (1987) 115-131.
[2] C. Ling, G. Hellgren, M. Gebre-Medhin, K. Dillner, H. Wennbo, B. Carlsson, H. Billig, Endocrinology 141 (2000) 3564-3572.

[3] C. Ling, L. Svensson, B. Oden, B. Weijdegard, B. Eden, S. Eden, H. Billig, J. Clin. Endocrinol. Metab. 88 (2003) 1804-1808.

[4] C. Schindler, Exp. Cell Res. 253 (1999) 7-14.

[5] J.M. Stephens, R.F. Morrison, Z.D. Wu, S.R. Farmer, Biochem. Biophys. Res. Commun. 262 (1999) 216-222.

[6] S.J. Yarwood, E.M. Sale, G.J. Sale, M.D. Houslay, E. Kilgour, N.G. Anderson, J. Biol. Chem. 274 (1999) 8662-8668.

[7] C.A. Shang, M.J. Waters, Mol. Endocrinol. 17 (2003) 2494-2508.

[8] R. Nanbu-Wakao, Y. Morikawa, I. Matsumura, Y. Masuho, M.A. Muramatsu, E. Senba, H. Wakao, Mol. Endocrinol. 16 (2002) 1565 1576.

[9] Z.E. Floyd, J.M. Stephens, Diabetes 52 (2003) 308-314.

[10] S. Teglund, C. Mckay, E. Schuetz, J.M. van Deursen, D. Stravopodis, D.M. Wang, M. Brown, S. Bodner, G. Grosveld, J.N. Ihle, Cell 93 (1998) 841-850.

[11] J.N. Fain, J.H. Ihle, S.W. Bahouth, Biochem. Biophy. Res. Commun. 263 (1999) 201-205.

[12] J.C. Hogan, J.M. Stephens, Diabetes 54 (2005) 1968-1975.

[13] S. Zvonic, P. Cornelius, W.C. Stewart, R.L. Mynatt, J.M. Stephens, J. Biol. Chem. 278 (2003) 2228-2235.

[14] J.D. Ritzenthaler, R.H. Goldstein, A. Fine, A. Lichtler, D.W. Rowe, B.D. Smith, Biochem. J. 280 (Pt 1) (1991) 157-162.

[15] C. Nohammer, Y. El Shabrawi, S. Schauer, M. Hiden, J. Berger, S. Forss-Petter, E. Winter, R. Eferl, R. Zechner, G. Hoefler, Eur. J. Biochem. 267 (2000) 1254-1260.

[16] C.Y. Fan, J. Pan, N. Usuda, A.V. Yeldandi, M.S. Rao, J.K. Reddy, J. Biol. Chem. 273 (1998) 15639-15645.

[17] T. Hashimoto, T. Fujita, N. Usuda, W. Cook, C. Qi, J.M. Peters, F.J. Gonzalez, A.V. Yeldandi, M.S. Rao, J.K. Reddy, J. Biol. Chem. 274 (1999) 19228-19236.

[18] A. Kassam, J.P. Capone, R.A. Rachubinski, Mol. Cell Endocrinol. 176 (2001) 49-56.

[19] M. Vazquez, N. Roglans, A. Cabrero, C. Rodriguez, T. Adzet, M. Alegret, R.M. Sanchez, J.C. Laguna, Mol. Cell Biochem. 216 (2001) 71-78.

[20] B. Olsson, Y. Bohlooly, O. Brusehed, O.G. Isaksson, B. Ahren, S.O. Olofsson, J. Oscarsson, J. Tornell, Am. J. Physiol. Endocrinol. Metab. 285 (2003) E504-E511.

[21] D.J. Flint, N. Binart, J. Kopchick, P. Kelly, Pituitary 6 (2003) 97-102. 